Original Article

\title{
The Effects of Squat Exercises in Postures for Toilet Use on Blood Flow Velocity of the Leg Vein
}

\author{
Jun Ho Eom, $\mathrm{PT}^{1)}$, Sin Ho Chung, PhD, $\left.\mathrm{PT}^{2}\right)^{*}, \mathrm{JAe}_{\mathrm{Aun}}$ Shim, PhD, PT, OT ${ }^{1)}$ \\ 1) Department of Physical Therapy, Baekseok University, Republic of Korea \\ 2) Hanyang University Medical Center: 222-1 Wangsimni-ro, Seongdong-gu, Seoul 133-792, Republic of \\ Korea
}

\begin{abstract}
Purpose] The purpose of this study was to identify the effects of squat exercises performed in toiletusing postures on the blood flow velocity of the lower extremities for the prevention of deep vein thrombosis. [Subjects] The subjects were 28 students who were attending B University in Cheonan. They were divided into a group of 14 subjects of sitting toilet users and a group of 14 subjects of squat toilet users. [Methods] The subjects performed squat exercises in different toilet-using postures and we investigated the changes in blood flow velocity. [Results] The variations in blood flow velocities before and after the exercises showed significant differences in both groups but the differences between the two groups were not significant. [Conclusion] Based on the results of this study, we consider squat exercises are effective at improving the variation in lower-extremity blood flow velocity when using a toilet.

Key words: Blood flow velocity, Squat exercises, Toilet-using postures
\end{abstract}

(This article was submitted Feb. 14, 2014, and was accepted Mar. 31, 2014)

\section{INTRODUCTION}

Squatting positions refer to positions in which the shoulder is placed on the knee, while the ankle, knee, and hip joints are bent. These positions are universal motions among Asians, including Koreans, that are repeatedly undertaken for daily living activities, agricultural activities, or work ${ }^{1)}$.

If squatting positions are undertaken repeatedly for long periods of time, the blood vessels in the lower extremities will be compressed, and the blood flow velocity will decrease. If the wall of the lower-extremity vein is damaged, blood flow congestion and/or excessive coagulation may overcome the tendency to inhibit thrombus formation, and deep vein thrombosis (DVT) may occur in the lower extremity $^{2)}$. DVT is a major public health challenge with an incidence rate of $0.3 \%$ in the general elderly population ${ }^{3)}$. DVT prevention is crucial and cost effective for critically ill patients. DVT tends to expand into proximal veins and/ or pulmonary emboli ${ }^{4}$.

Examples of squatting positions undertaken for a long period of time in daily living activities include defecating activities when using a toilet. Previous studies of squatting positions have reported that $22.5 \%$ of the subjects could not perform squatting positions ${ }^{5)}$, due to problems associated with ankle joint movements ${ }^{6}$.

\footnotetext{
*Corresponding author. Sing Ho Chung (E-mail: wwin72@ empas.com)

(C) The Society of Physical Therapy Science. Published by IPEC Inc. This is an open-access article distributed under the terms of the Creative Commons Attribution Non-Commercial No Derivatives (by-ncnd) License $<$ http://creativecommons.org/licenses/by-nc-nd/3.0/>.
}

Previous studies have also reported that weight bearing exercises such as squats were functional, because these exercises require the movement of more joints than non weight bearing exercises, promote functional patterns of muscle mobilization, and stimulate proprioceptive senses ${ }^{7)}$. Also, static resistance exercises increase vascular compliance more than aerobic exercises ${ }^{8)}$, and one-shot gradual maximum exercises induce significant increases in the blood flow velocity in the middle cerebral artery ${ }^{9}$.

In a previous study that measured the degrees of inconvenience in relation to lower-extremity positions, high degrees of inconvenience were shown at knee joint angles of $60^{\circ}$ and $90^{\circ}$, and low degrees of inconvenience were shown at chair heights of $40 \mathrm{~cm}$ and $20 \mathrm{~cm}$ and in cross-legged sitting positions ${ }^{10)}$.

Although studies have been conducted on the degrees of inconvenience related to lower-extremity positions, few studies of the effects of lower-extremity positions on the blood flow velocity of the lower extremities have been conducted.

Therefore, this study examined the effects of squat exercises performed in toilet-using postures on the blood flow velocity of the lower extremities for the prevention of DVT.

\section{SUBJECTS AND METHODS}

\section{Subjects}

This study was conducted with 28 students who were attending B University in Cheonan. They were divided into a group of 14 subjects ( 6 males, 8 females) of sitting toilet users and a group of 14 subjects ( 7 males, 7 females) of squat toilet users. The mean age of the sitting toilet-using 
group was $22.78 \pm 2.93$ years, the mean height was 165.71 $\pm 6.67 \mathrm{~cm}$, and the mean weight was $57.92 \pm 11.39 \mathrm{~kg}$. The mean age of the squat toilet-using group was $23.07 \pm$ 2.58 years, the mean height was $168.00 \pm 8.19 \mathrm{~cm}$, and the mean weight was $62.07 \pm 11.67 \mathrm{~kg}$. When selecting the subjects, those who had limited range of lower-extremity joint motion, those who had problems found by ultrasonic diagnosis, and those who had vasomotor dysfunction ${ }^{11)}$ were excluded. This study was approved by the Institutional Review Board of Bronco Memorial Hospital.

\section{Methods}

To examine the effects of squat exercises in different toilet-using postures on changes in blood flow velocity, the subjects were instructed to perform sitting toilet-using postures and squat toilet-using postures.

For the sitting toilet-using postures, the subjects were instructed to sit on a model toilet with a height of $40 \mathrm{~cm}$, the standard height of pedestal toilets, and place their feet as they usually did, while maintaining their back upright. For the squat toilet-using postures, the subjects were instructed to sit with their heels $30 \mathrm{~cm}$ apart from each other, which is the standard width of squat toilets.

Blood flow velocities were measured using ultrasonic imaging equipment (LOGIQ e Portable, GE Inc., USA) with $10 \mathrm{MHz}$ linear probes. To take images of the same measurement regions of the subjects, the region where the right medial ankle bone meets the second toe (the location where the dorsal venous arch and the great saphenous vein meet) was marked using the color flow mode of the ultrasonic equipment ${ }^{12)}$. Blood flow velocities were measured in individual measurement postures and measured again 15 minutes later. A rest was given for 20 minutes thereafter.

Squat exercises were performed with the subject's arms folded and the subject's back maintained upright while putting the feet at shoulder width and maintaining a knee angle of $60^{\circ 13)}$. Each motion was maintained for 10 seconds, and 5 sets of 10 repetitions were performed. A rest of one minute was given after each set. Blood flow velocities were measured in individual measurement postures after the exercises and remeasured 15 minutes later. Variations in blood flow velocities were measured using analytic software (R5.X.x software for the LOGIQ e ultrasound system, GE Inc., USA).

Statistical analyses were conducted using SPSS for Windows (version 18.0). The data were analyzed using independent t-test to verify the homogeneity of demographic characteristics and dependent variables. The data were also analyzed using the paired t-test to compare differences in the variations in blood flow velocities before and after the exercises and the independent t-tests for comparisons between the two groups. The significance level was chosen as 0.05 .

\section{RESULTS}

The variations in blood flow velocities before and after the exercises showed significant differences, with a change from $1.83 \pm 1.13 \mathrm{~cm} / \mathrm{sec}$ to $1.18 \pm 0.88 \mathrm{~cm} / \mathrm{sec}$ in the sitting
Table 1. Comparison of variations in blood flow velocities $(N=28)$

\begin{tabular}{lcc}
\hline & $\begin{array}{c}\text { Sitting toilet-using } \\
\text { group }\end{array}$ & $\begin{array}{c}\text { Squat toilet-using } \\
\text { group }\end{array}$ \\
\hline Pre squat exercise & $1.83 \pm 1.13$ & $3.38 \pm 2.10$ \\
Post squat exercise & $1.18 \pm 0.88^{*}$ & $2.01 \pm 1.23^{*}$ \\
\hline
\end{tabular}

Unit: $\mathrm{cm} / \mathrm{sec} .{ }^{*} \mathrm{p}<0.05$. Mean \pm SD.

toilet-using group and a change from $3.38 \pm 2.10 \mathrm{~cm} / \mathrm{sec}$ to $2.01 \pm 1.23 \mathrm{~cm} / \mathrm{sec}$ in the squat toilet-using group $(\mathrm{p}<0.05)$, but the differences between the two groups were not significant (Table 1).

\section{DISCUSSION}

Koreans frequently use squatting motions due to their cultural tradition. The motions are comparable to the motions used to sit on chairs in Western culture. Squatting positions lead to complaints of pain in the lower leg rather than in the lower back or the upper leg, because squat positions move the center of mass forward and increase loads on the ankles and the feet ${ }^{1)}$. Performing activies of daily living or work in squatting positions with diverse knee joint angles for a long time affects the blood flow velocity of the lower extremities. If the motions that affect the blood flow velocity of the lower extremities are repeatedly performed, deformation and defects may occur in the knee cartilage and the collagen fiber networks of the meniscus, even though the motions' momentary loads are not large ${ }^{14-16)}$, and squatting positions for long periods of time may cause musculoskeletal system diseases in workers ${ }^{17)}$.

In this study, the variations in blood flow velocities in the different toilet-using postures after squat exercises showed significant decreases from the variations before the exercises. Squat exercises are closed-chain exercises, which are widely used in knee joint rehabilitation because of their functional characteristics, including simultaneous contractions of the quadriceps femoris muscle and the hamstring muscle. In addition decreases in the anterior-posterior kneefemoral displacement, decreases in the pressure on the knee joint, and selective contraction of the vastus medialis muscle have been reported ${ }^{18,}{ }^{19}$. Resistance exercises, which are one of the best methods for developing muscle strength, stimulate the body to promote interactions between skeletal muscles and neuromuscles, and also affect the nervous system by increasing the number of motor units, thereby improving muscle strength and increasing muscle size ${ }^{20,21)}$.

In previous studies of blood flow rates, Zhang et al. ${ }^{22)}$ suggested that increases in arterial tension would increase blood flow velocity in the arteries. Sato et al. ${ }^{23)}$ reported increases in blood flow velocities in the carotid and vertebral arteries after exercises at $40 \%, 60 \%$, and $80 \%$ of $\mathrm{VO} 2$ peak compared to at rest, indicating increases in blood flow after exercises, and Jang ${ }^{24)}$ showed there was a significant decrease in the variation in the average blood flow velocity of the left subclavian artery, from $38.2 \mathrm{~cm} / \mathrm{sec}$ before a dance exercise to $33.4 \mathrm{~cm} / \mathrm{sec}$ after the exercise. Therefore, although the measurement sites were different, we consider 
the decrease in the variation in blood flow velocities seen in our present study is attributable to the fact that the squat exercises stimulated the temperature control centers in the muscles, triggering the spinal reflex to increase blood flow rates.

In this study, differences in the variation in blood flow velocities between the types of toilets were not significant, and the variation in blood flow velocities was found to be lower when sitting toilets were used.

Based on the results of this study, we consider squat exercises are effective at reducing the variation in lowerextremity blood flow velocity and can be recommended for increasing blood flow rates. Limitations of this study were that the subjects comprised males and females in their twenties, and thus the results cannot be generalized to all age groups. Also, diverse sitting postures were not investigated, and patients with lower-extremity blood flow disorders were not included. In future studies, the effects of exercises performed for a long period of time and blood flow rates in diverse sitting postures should be compared.

\section{REFERENCES}

1) Chung MK, Lee I, Kee D: Effect of stool height and holding time on postural load of squatting postures. Int J Ind Ergon, 2003, 32: 309-317. [CrossRef]

2) Phillips L, Macmillan A, Tweed C: Review of intermittent pneumatic compression: An evidence-based therapeutic modality for the prevention of avoidable deep vein thrombosis. J Integr Care Pathw, 2004, 8: 55-58.

3) Hong KC, Kim H, Kim JY, et al.: Risk factors and incidence of deep vein thrombosis in lower extremities among critically ill patients. J Clin Nurs, 2012, 21: 1840-1846. [Medline] [CrossRef]

4) Weill-Engerer $S$, Meaume $S$, Lablou A, et al. Risk factors for deep vein thrombosis in inpatients aged 65 and older: A case-control multicenter study. J Am Geriatr Soc, 2004, 52: 1299-1304.

5) Kasuyama T, Sakamoto M, Nakazawa R: Ankle joint dorsiflexion measurement using the deep squatting posture. J Phys Ther Sci, 2009, 21 195-199. [CrossRef]

6) Zelle J, Barink M, Loeffen R, et al.: Thigh-calf contact force measurements in deep knee flexion. Clin Biomech (Bristol, Avon), 2007, 22: 821826. [Medline] [CrossRef]

7) Selseth A, Dayton M, Cordova ML, et al.: Quadriceps concentric EMC activity is greater than eccentric EMG activity during the lateral step-up exercise. J Sport Rehabil, 2000, 9: 124-134.

8) Park KH, Choi J: Effect of acute resistant exercise on blood vessel elasticity, blood pressure, pulse pressure in the middle aged. Journal of Coaching Development, 2010, 12: 259-268.

9) Wee SD, Kang SH. Effects of Acute Exercise on Cerebral Blood Flow Velocity, Respiratory Gases and EEG. Journal of Sport and Leisure Studies, 2008, 32: 991-998.

10) Kong YK, Kim DM, Lee S, et al.: Evaluation of the effects of lower-limb postures on the subjective discomfort, heart rate and EMGs of lower extremity muscles. J Ergonomics Soc Korea, 2009, 28: 9-19. [CrossRef]

11) Cameron MH, Monroe LG: Physical Rehabilitation Evidence-Based Examination Evaluation and Intervention. Philadelphia, Elsevier. 2007, p 493.

12) Chung MS, Lee YD, Chung IH: Morphology of the cutaneous vein in the dorsal foot and the ankle. Korean J Phys Anthropol, 1993, 6: 119-127.

13) Tang SF, Chen CK, Hsu R, et al.: Vastus medialis obliquus and vastus lateralis activity in open and closed kinetic chain exercises in patients with patellofemoral pain syndrome: an electromyographic study. Arch Phys Med Rehabil, 2001, 82: 1441-1445. [Medline] [CrossRef]

14) Aspden RM, Yarker YE, Hukins DW: Collagen orientations in the meniscus of the knee joint. J Anat, 1985, 140: 371-380. [Medline]

15) Cohen B, Lai WM, Mow VC: A transversely isotropic biphasic model fo unconfined compression of growth plate and chondroepiphysis. J Biomech Eng, 1998, 120: 491-496. [Medline] [CrossRef]

16) Insall J: Current Concepts Review: patellar pain. J Bone Joint Surg Am, 1982, 64: 147-152. [Medline]

17) Keyserling WM, Punnett L, Fine LJ: Trunk posture and back pain: identification and control of occupational risk factors. Appl Ind Hyg, 1988, 3 : 87-92. [CrossRef]

18) Gorsuch J, Long J, Miller K, et al.: The effect of squat depth on multiarticular muscle activation in collegiate cross-country runners. J Strength Cond Res, 2013, 27: 2619-2625. [Medline] [CrossRef]

19) Newman SA, Jones G, Newham DJ: Quadriceps voluntary activation a different joint angles measured by two stimulation techniques. Eur J Appl Physiol, 2003, 89: 496-499. [Medline] [CrossRef]

20) Enoka RM: Muscle strength and its development. New perspectives. Sports Med, 1988, 6: 146-168. [Medline] [CrossRef]

21) Staron RS, Malicky ES, Leonardi MJ, et al.: Muscle hypertrophy and fast fiber type conversions in heavy resistance-trained women. Eur J Appl Physiol Occup Physiol, 1990, 60: 71-79. [Medline] [CrossRef]

22) Zhang R, Behbehani K, Levine BD: Dynamic pressure-flow relationship of the cerebral circulation during acute increase in arterial pressure. $\mathrm{J}$ Physiol, 2009, 587: 2567-2577. [Medline] [CrossRef]

23) Sato K, Ogoh S, Hirasawa A, et al.: The distribution of blood flow in the carotid and vertebral arteries during dynamic exercise in humans. J Physiol, 2011, 589: 2847-2856. [Medline] [CrossRef]

24) Jang YW: Effect of dance sports activity on the health-physical fitness and artery blood flow variables in elementary school girl child. Korean J Sports Sci, 2013, 22: 1025-1034. 